\title{
DEVELOPMENT OF SAFETY ASSESSMENT SYSTEM FOR FOOD PREMISES
}

\author{
Nazmi 'Imran Makhilan', Nur Syafiqah Fauzan ${ }^{1,{ }^{*}}$, Nurhayati Shariffudin², and Amiruddin Mohd Zin ${ }^{3}$ \\ ${ }^{1}$ Faculty of Industrial Sciences and Technology, Universiti Malaysia Pahang, 26300 Pahang, Malaysia. \\ ${ }^{2}$ Hulu Selangor District Council, 44000 Kuala Kubu Bharu, Selangor, Malaysia. \\ ${ }^{3}$ Sik District Health Office, 08200 Sik, Kedah, Malaysia.
}

\begin{abstract}
Food safety issues have arising nowadays due to the lack of knowledge, attitude and practice (KAP) among food handlers. Lacking compliance among food handlers and food premises with the regulations and guidelines is also one of the causes that contribute to foodborne disease. Besides, lacking a systematic safety assessment system for food premises has hindered the improvement of food safety levels at the workplace. The study focuses on the development of a safety assessment system for food premises based on the Guideline for Grading System for Food Premises in Local Authority. The Safety Assessment System was developed by using Microsoft Excel. Validation of the system was conducted by getting feedback from food safety experts among government servants for further improvement. The System Usability Scale (SUS) test was done among two expert panels and the owner of food premises. The score for the SUS Test achieved 69.6 which is Grade C. The finding reveals that the developed system is considered above the average level, useable and succeeded.
\end{abstract}

\section{INTRODUCTION}

Food safety remains a major concern around the globe. Every year, millions of people in the world are hospitalized and even die after consuming contaminated food (World Health Organization, 2015). Besides, a previous study mentioned that there was an increase in cholera, food poisoning, and hepatitis A cases from the year 2009 until 2011, but there was a decrease in dysentery (Abdul-Mutalib et al., 2015). From the year 2011 until 2013, the number of cases relating to cholera, typhoid, and hepatitis A decreased, but dysentery showed an increment. Of those total cases related to foodborne illnesses, $70 \%$ of them were related to food service establishments. Food handlers play an important role in ensuring food safety and preventing food contamination throughout the chain of production, processing, storage, and preparation (Lee et al., 2017). According to the Department of Statistics Malaysia (2015), food poisoning in Malaysia recorded the highest incidence rate of 47.7 per 100,000 population which is about 14,433 cases in the year 2015 . Therefore, food premises are the most significant places that will contribute to the outbreaks of foodborne illness (Mun, 2020).

Ineffective food handling training, the use of untreated water for non-drinking purposes, and poor sanitation and hygiene are the primary risk factors of food poisoning in the country (MOH, 2014). Food handlers play the main role in ensuring food safety and the prevention of food poisoning. Researchers suggested that the food handlers who have knowledge of proper food handling practices could help to control food poisoning cases as they were the direct contact person with food, especially for ready-to-eat foods (Angelillo et al., 2000).

There are various previous studies done in Malaysia to assess the knowledge, attitude, and practices of food safety among food handlers. A study by Dora-liyana et al. (2018) in the Northern Region of Malaysia used a questionnaire to evaluate the level of food knowledge, attitude, and practices (KAP) among the food handlers from seven boarding schools. The same method was also used for the study in Selangor (Ismail et al., 2016) and at Kuala Pilah (Abdul-Mutalib et al., 2012) by using a self-administered questionnaire. Moreover, other previous assessments on knowledge, attitude, and practices (KAP) were conducted among food handlers in Penang (Shafie \& Azman, 2015) and among foodservice operations at the Universiti Kebangsaan Malaysia (UKM) (Sani \& Siow, 2014).

Besides, the safety assessment for food premises was also done by the Environmental Health division from the Ministry of Health in collaboration with the Local Authorities. Representatives from Local Authorities which consist of the Environmental Health Officer (EHO) and Assistant Environmental Health Officer (AEHO) used manual assessment for examining, inspecting, and grading on the food premises (Ministry of Housing and Local Government, 2014). The current method resulted in a long duration for the authority to assess and grade the food premises. Therefore, there is a need for an improvement in the assessment process to shorten the duration of the assessment. Thus, the current study aims to develop the safety assessment system for food premises based on the criteria stated by Food Act 1983 and the Guideline for Grading System for Food Premises in Local Authority Areas. The development of a Safety Assessment System for food premises will help in increasing the awareness of food safety among food handlers and reducing the foodborne diseases occurred among the public. 


\section{RESEARCH METHODOLOGY}

\section{System Development}

The framework of the Safety Assessment System was developed as shown in Figure 1 which covers the food premises and food handlers. The elements of the Safety Assessment System were design based on the Food Act 1983 and the Guideline for Grading Systems for Food Premises in Local Authority by the Ministry of Housing and Local Government. The content of the system is referred to as the Food Premises Examination and Grading Form from Environmental Health Division, Local Government Department. The element in the assessment was divided into eight sections. The first section is demographic data of the food premises and the details of the assessment. The other seven sections include different elements of assessment at food premises such as food preparation area, food serving area, delivery area, infrastructures or facilities, and maintenance of the premise.

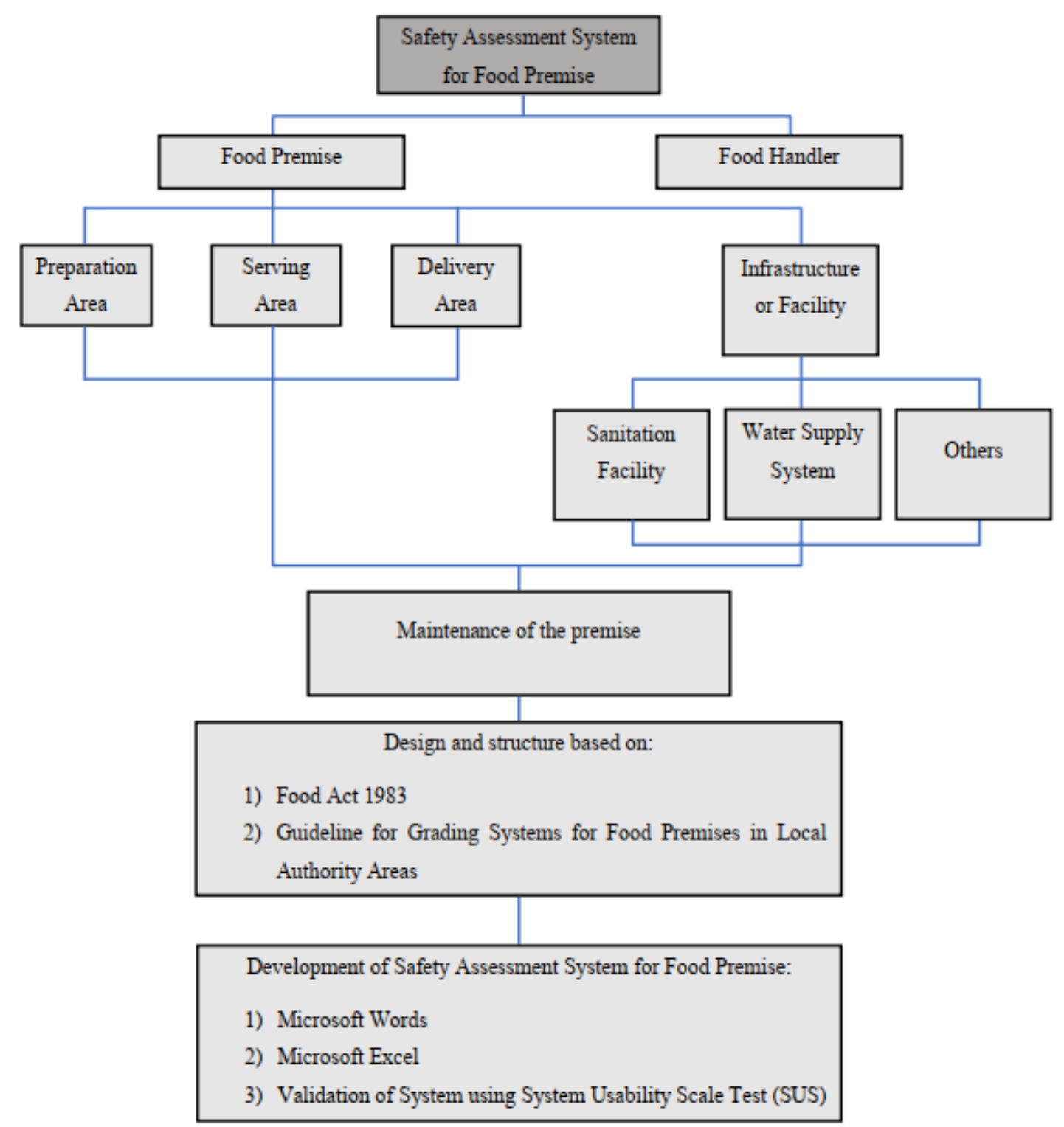

Figure 1: Framework of Safety Assessment System for Food Premise

\section{Framework Development Using Microsoft Software}

The framework for this system was developed by using Microsoft Word 2019 by referring to the standard assessment form from Food Premises Examination and Grading Form provided by the Local Authority (PBT) under the Environmental Health Division, Local Government Department, and Food Act 1983. The system was divided into two parts which are Food Premise and Food Handlers. 
The prototype system was designed and developed using Microsoft Excel. The development of the system was a fully functioning system that can auto-calculate, produce results, and grade the food premises that have been assessed by the end-users.

\section{System Usability Scale (SUS) Test}

A potential end-user that uses this prototype system evaluated the usability of this system by using the System Usability Scale (SUS) Test (Peres et al., 2013). About twelve end-users were selected in participating the System Usability Scale test. SUS is a standardized questionnaire that was designed as a method for the assessor to evaluate the usability of a system which consists of 10 items with five response options for respondents, from Strongly Agree to Strongly Disagree. It is important to allow the developer to develop the system and go through an interactive process with users. The evaluation of this test is based on the total SUS score filled up by the users (Peres et al., 2013). The grade was given based on the total score by referring to the Curved Grading Scale. Table 1 and Table 2 show the System Usability Scale Questionnaire and Curved Grading Scale.

Table 1: System Usability Scale Questionnaire.

\begin{tabular}{|c|c|c|c|c|c|}
\hline & \multirow[t]{2}{*}{ The System Usability Scale Standard Version } & \multicolumn{2}{|c|}{ Strongly Disagree } & \multicolumn{2}{|c|}{ Strongly Agree } \\
\hline & & 1 & 2 & 3 & 4 \\
\hline 1 & I think that I would like to use this system frequently. & 0 & 0 & 0 & 0 \\
\hline 2 & I found the system unnecessarily complex. & 0 & 0 & 0 & 0 \\
\hline 3 & I thought the system was easy to use. & 0 & 0 & 0 & 0 \\
\hline 4 & $\begin{array}{l}\text { I think that I would need the support of a technical } \\
\text { person to be able to use this system. }\end{array}$ & 0 & 0 & 0 & 0 \\
\hline 5 & $\begin{array}{l}\text { I found the various functions in this system were well } \\
\text { integrated. }\end{array}$ & 0 & 0 & 0 & 0 \\
\hline 6 & $\begin{array}{l}\text { I thought there was too much inconsistency in this } \\
\text { system. }\end{array}$ & 0 & 0 & 0 & 0 \\
\hline 7 & $\begin{array}{l}\text { I would imagine that most people would learn to use } \\
\text { this system very quickly. }\end{array}$ & 0 & 0 & 0 & 0 \\
\hline 8 & I found the system very awkward to use. & 0 & 0 & 0 & 0 \\
\hline 9 & I felt very confident using the system. & 0 & 0 & 0 & 0 \\
\hline 10 & $\begin{array}{l}\text { I needed to learn a lot of things before I could get } \\
\text { going with this system. }\end{array}$ & 0 & 0 & 0 & 0 \\
\hline
\end{tabular}

Table 2: Curved Grading Scale.

\begin{tabular}{cc}
\hline Grade & SUS \\
\hline A+ & $84.1-100$ \\
\hline A & $80.8-84.0$ \\
\hline A- & $78.9-80.7$ \\
\hline B + & $77.2-78.8$ \\
\hline B & $74.1-77.1$ \\
\hline B- & $72.6-74.0$ \\
\hline C + & $71.1-72.5$ \\
\hline C & $65.0-71.0$ \\
\hline C- & $62.7-64.9$ \\
\hline D & $51.7-62.6$ \\
\hline F & $0-51.6$ \\
\hline
\end{tabular}

\section{Semi-Structured Interview}

The system was presented to two experts which are the representatives from the Local Authority and the Ministry of Health. After the system was presented, an evaluation form was provided for the respondents to give feedback for the improvement of the developed prototype system. 


\section{RESULTS AND DISCUSSION}

Comparison Between Manual Assessment and Safety Assessment System for Food Premise

\section{Manual Assessment}

The current method used by the local authority in performing the safety assessment at food premises is using the Food Premise Examination and Grading Form by the Local Government Department. The premise score is calculated manually to find the grade score by referring to the standard grading table.

\section{Safety Assessment System for Food Premise}

The developed prototype safety assessment system is an innovation from the previous manual assessment method. The researchers have made some improvements to the current tool while conducting the assessment. The prototype system can be used via mobile phones and laptops instead of using the manual form during the assessment. Next, the total score of each item assessed is automatically calculated to get the final score. Thus, the grading for the food premise is also automatically generated by the system after the assessment is done. For record-keeping, it is easier for the end-users where the new assessment data that is done can be accessed by another person from another place.

\section{Development of Safety Assessment System for Food Premises}

Safety Assessment System for Food Premises is developed by using Microsoft Excel. This system can be accessed using handphones and laptops. End-users can use this system to do the safety assessment at food premises. Figure 2 shows the flowchart of the system guideline.

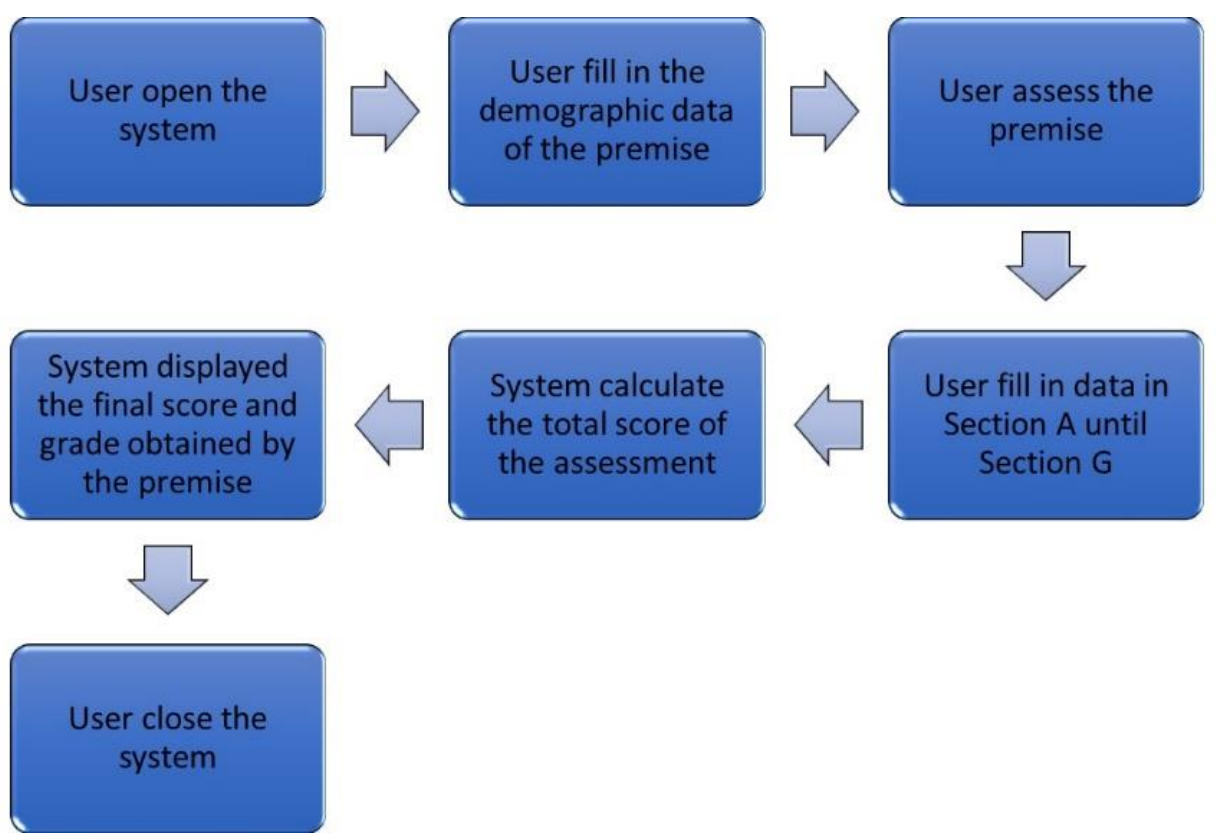

Figure 2: Flowchart of the System User Guideline

Figure 2 shows the flow of the safety assessment system that works in guiding the user to assess the food premise. First, users should access the system by using Microsoft Excel software either via mobile phones or laptops. In the beginning, the user must fill up the demographic data interface to store the details of the food premise. In the system, the user will be guided to fill up the data in Section A until Section G before assessing the premise. The system will automatically calculate the total score of the assessment. Finally, the system will display the final score and grade obtained by the premise.

\section{Details Development of Safety Assessment System for Food Premises Demographic Data Interface}

A demographic data page is used to collect the information related to the food premise such as the owner information, food premise address, and the total number of food handlers. This interface is used to collect the inspection details of food on the premise such as the serial number, date, and time of inspection. Then, the system will guide the user to move to 
the next section by using the navigation button located on the right side of the table. Figure 3 shows the interface of the demographic data.

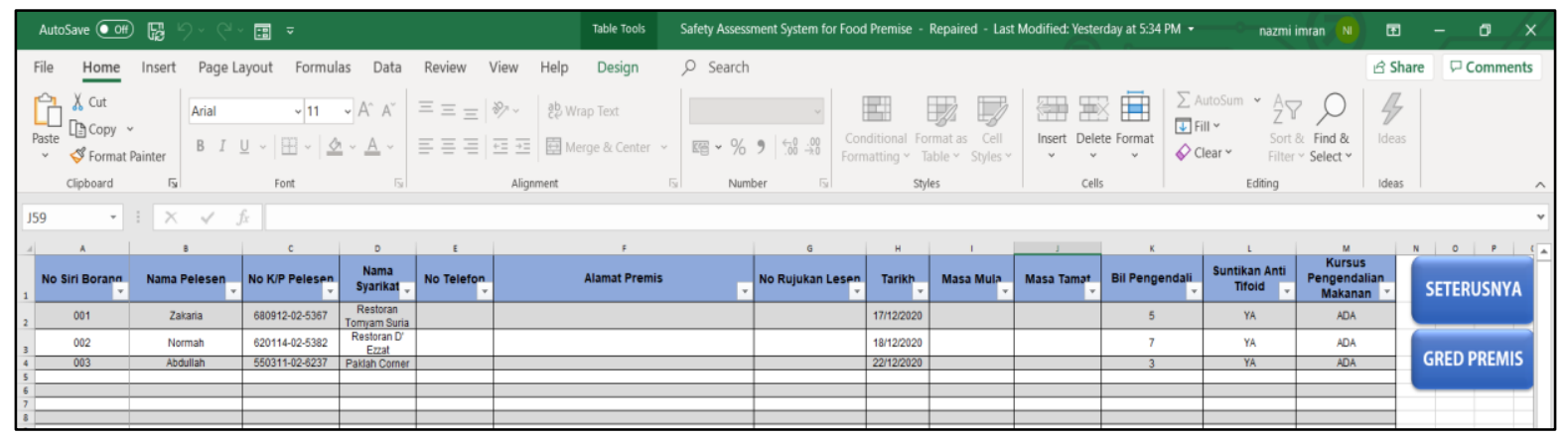

Figure 3: Demographic Data Interface

\section{Form Preparation}

The form was created and can be used by the user by clicking the "form button" at the ribbon of Microsoft Excel. Figure 4 shows the location of the "form button". Figure 7 shows the example of the form interface.

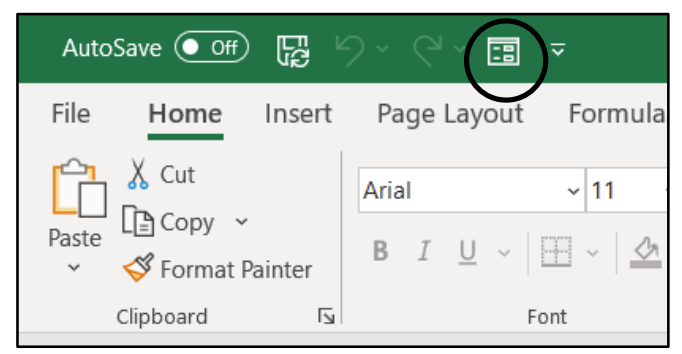

Figure 4: Form button.

\begin{tabular}{|c|c|c|}
\hline Maklumat Premis & & $?$ \\
\hline № Siri Borang: & $\wedge$ & New Record \\
\hline Nama Pelesen: & & New \\
\hline No $\underline{K} / \mathrm{P}$ Pelesen: & & Delete \\
\hline Nama Syarikat: & & Restore \\
\hline No Ielefon: & & \\
\hline Alamat Premis: & & Find prev \\
\hline No Ruiukan Lesen: & & Find $\underline{N}$ ext \\
\hline Tarikh: & & Criteria \\
\hline Masa Mula: & & Close \\
\hline Masa Tamat: & & \\
\hline Bill Pengendali: & & \\
\hline Suntikan Anti Tifoid: & & \\
\hline Kursus Pengendalian Makanan: & $\checkmark$ & \\
\hline
\end{tabular}

Figure 5: Form Interface

This system could be accessed using mobile phones too. Thus, users can also fill-up the form by using the Microsoft Excel app on a mobile phone. Therefore, this system makes it easier for the end-users. Figure 6 shows the interface of the system on a mobile phone. 


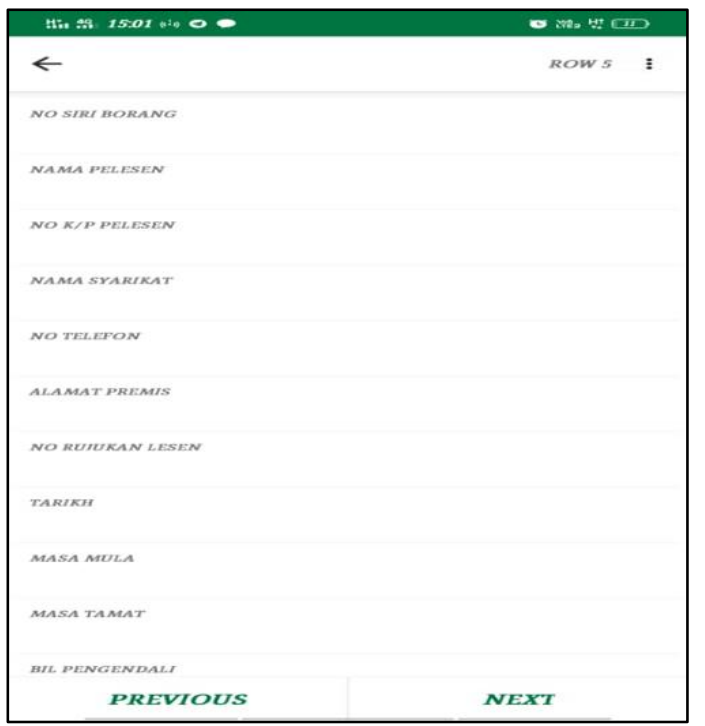

Figure 6: Interface in Mobile Phone App

\section{Safety Assessment}

Safety assessment is used to assess the safety level at food premises. The system consists of seven sections that are labelled with Section A until Section G. Each section consists of different elements of assessment. The user is guided by a serial number to track the assessment data. Figure 7 until Figure 13 shows the interface for each section of the safety assessment. This system provides an easier, effective, and user-friendly way to do the assessment. It will make the targeted users feel at ease in conducting the safety assessment at the food premise. Besides, this current prototype will help endusers, especially local authorities, in storing and tracking the assessment record that has already been done. It is important to provide and maintain the information process to make sure workers can assess specific information when needed (Aziz et al., 2014).

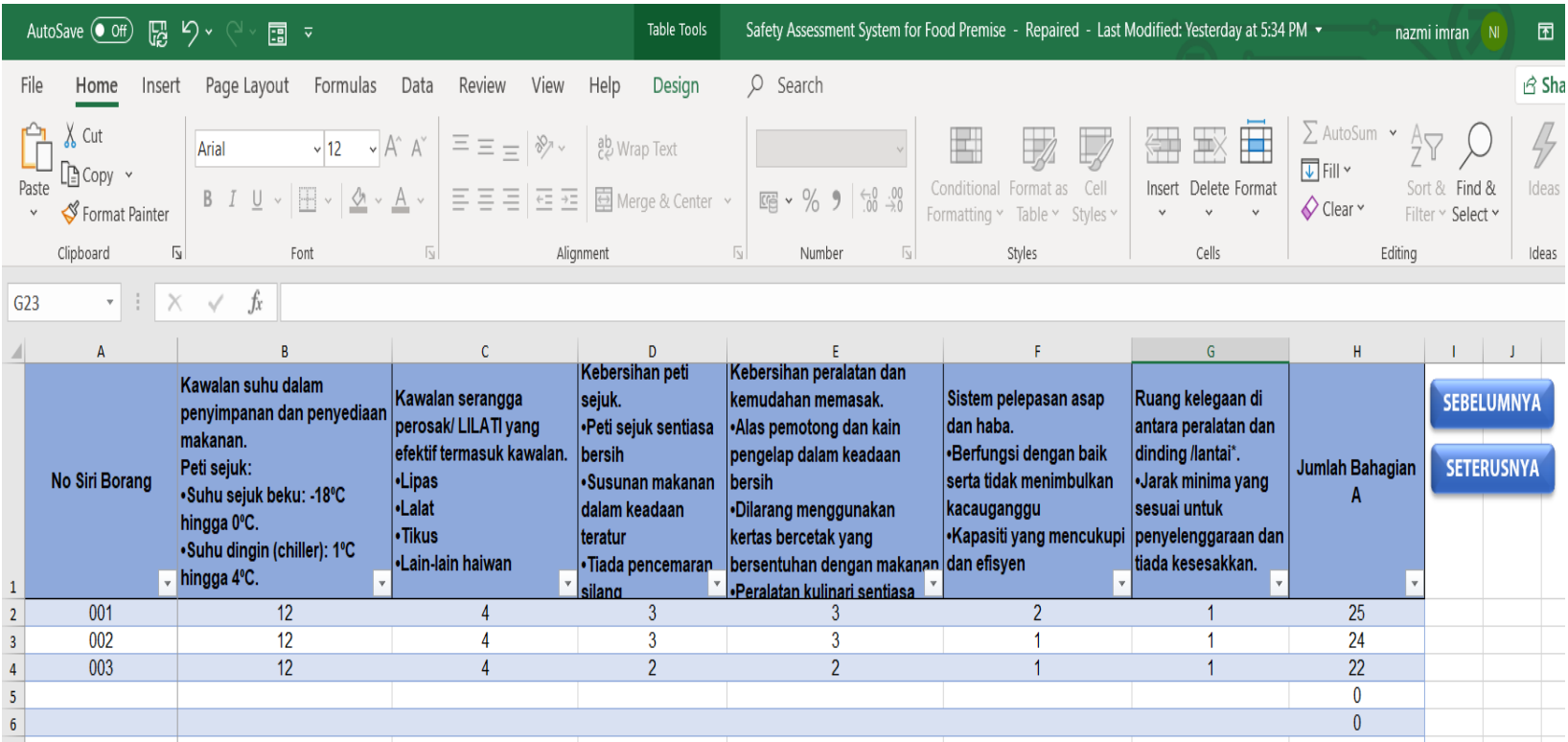

\section{Figure 7: Section A}

This interface allows users to give a score on the assessment of the food preparation area. This interface assists the user to assess the cleanliness of the food preparation equipment and area, the condition of the smoke and heat emission system, and the temperature control in food storage and preparation. Hertzman and Barrash (2007) mentioned that not checking temperatures before serving food, storing hot or cold food improperly, using incorrect cooking or service equipment, and not properly cleaning and sanitizing equipment may lead to potential food safety violations. 


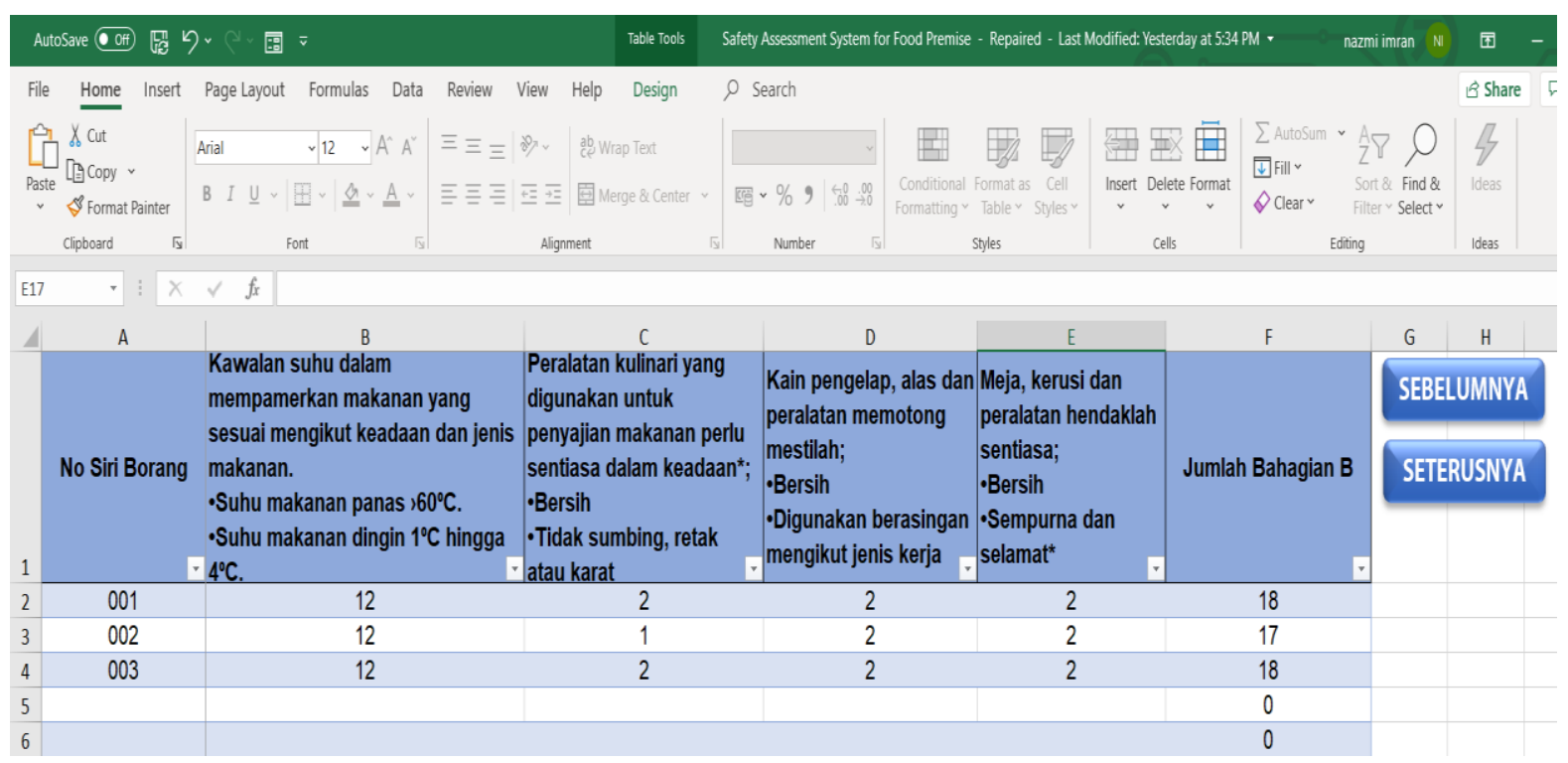

Figure 8: Section B

Figure 8 shows the interface that allows users to give a score on the assessment at the food serving area. This section contains four elements to be assessed such as the temperature of the food and serving area, the condition of culinary equipment, and the cleanliness of chairs and tables. Food temperature is one of the important parameters in food safety. Workers must check the food temperature when moving food to or from warming or refrigerated equipment. The improper food temperature will encourage the presence of microorganisms which can cause foodborne illnesses (Hertzman \& Barrash, 2007).

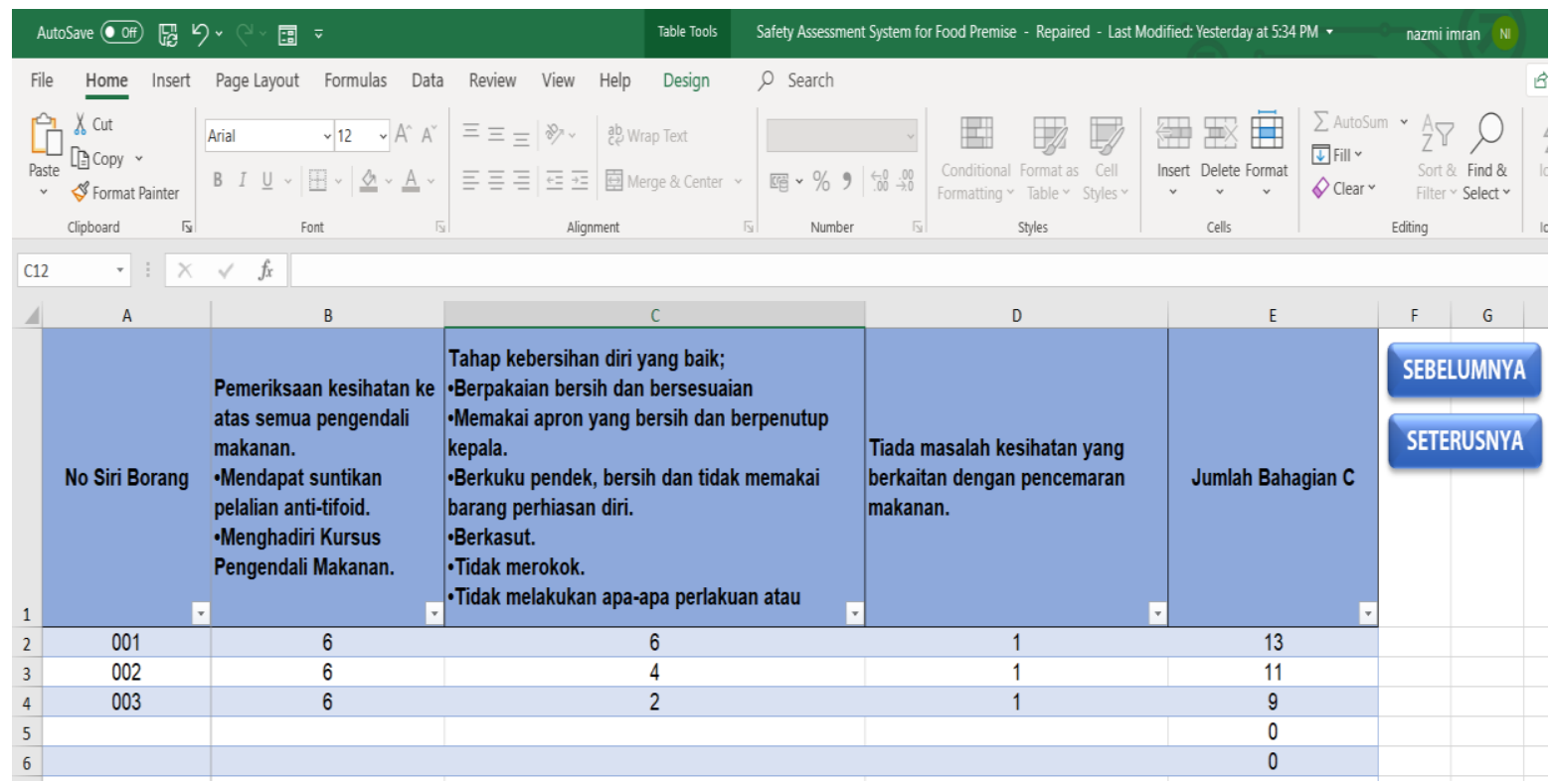

Figure 9: Section C

Figure 9 shows the interface that allows users to give a score on the assessment among the food handlers. This interface contains three elements of assessment on food handlers including health status, level of self-cleanliness, and the record of health inspection of every food handler at the premise. A study by Sani et al. (2018) mentioned that lack of proper hygiene among food handlers will lead to foodborne disease among consumers. Besides, poor food hygiene contributes to more than $50 \%$ of foodborne disease outbreaks in Malaysia (Saad et al., 2013). 


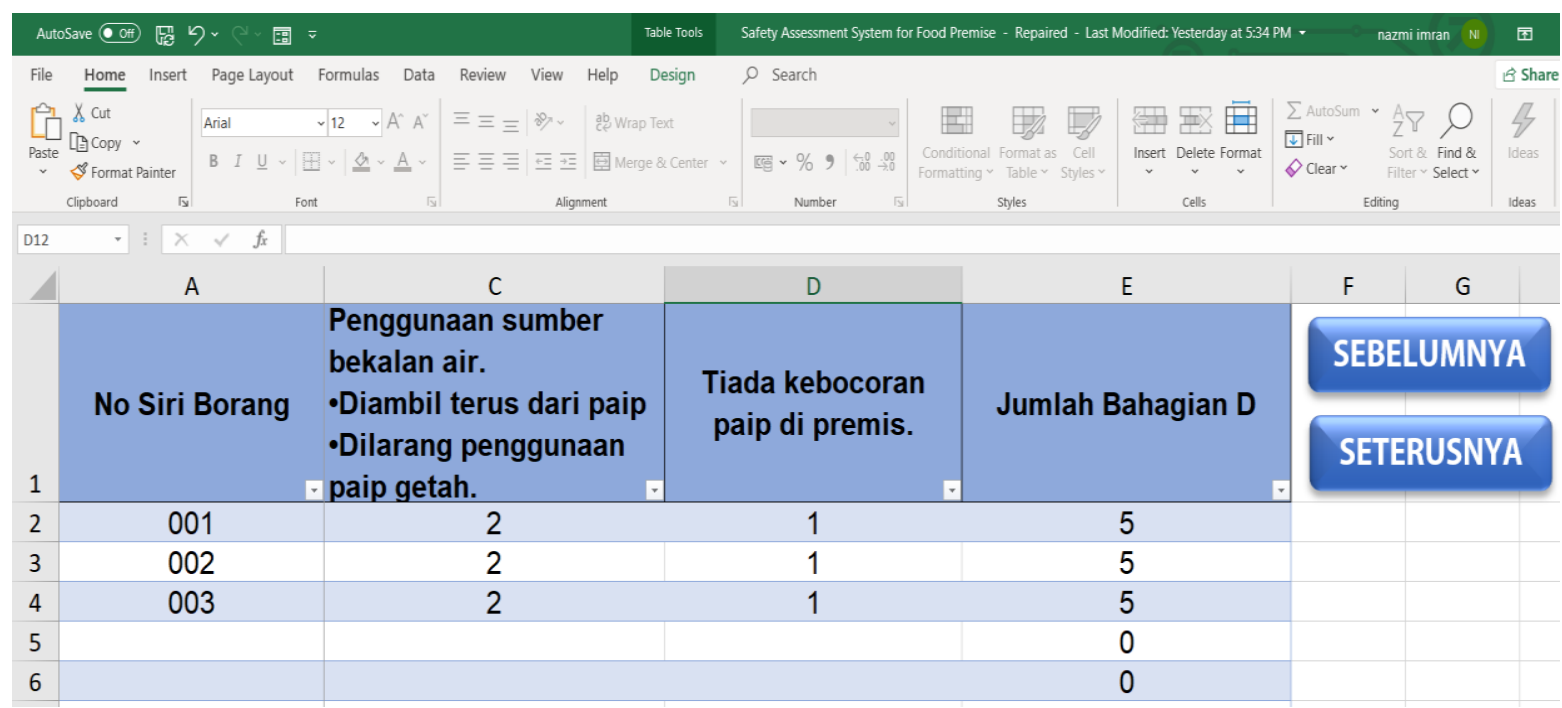

\section{Figure 10: Section D}

The interface shown in Figure 10 allows users to give a score on the water supply system. This page contains three elements of the assessment on the water supply system such as the source of water supply and the condition of water pipes. To ensure the food will not become unsafe or unsuitable for human consumption, it is recommended to make sure all food service facilities and food handlers comply with the requirement of the food standard code (Bou-Mitri et al., 2018).

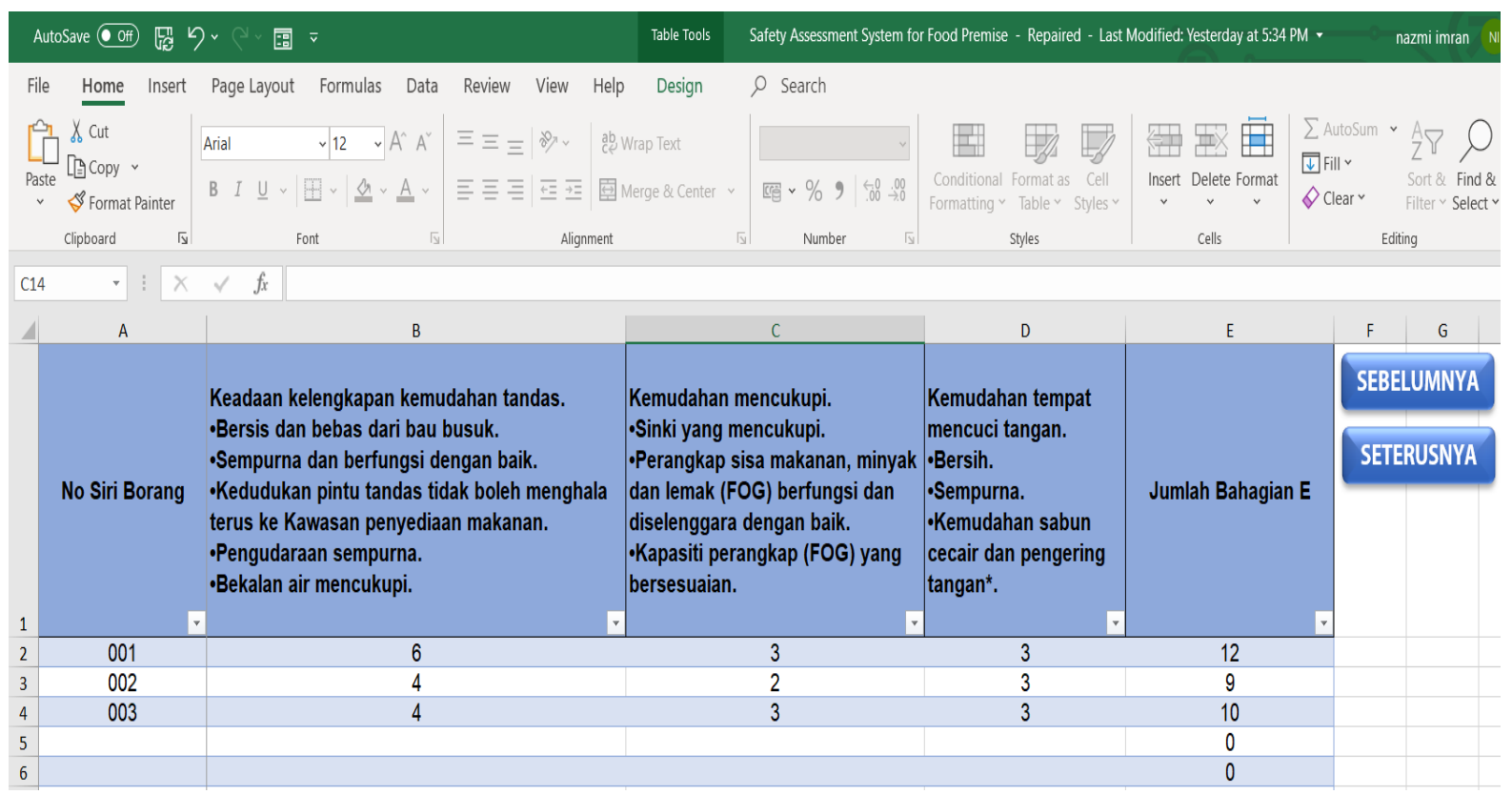

Figure 11: Section E

The interface above allows users to fill up the score on the sanitation facilities at the premise. This section has three elements of assessment including the condition of toilet facilities, sink, and other facilities provided by the premise. 


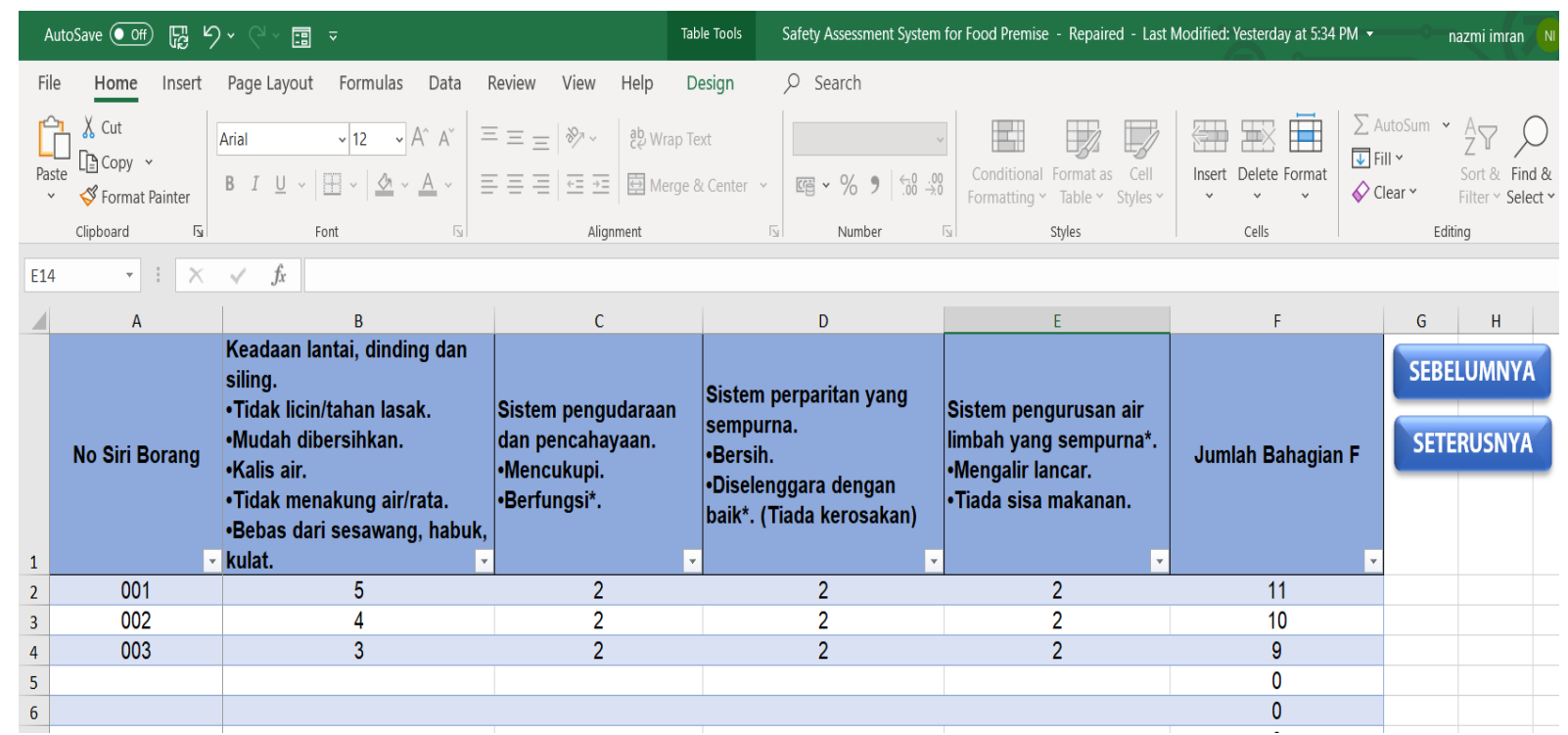

Figure 12: Section F

The interface in Figure 12 allows users to fill up the score on the structure and maintenance of the premise. This section has four elements of assessment such as assessment on the condition of floor, wall, and ceiling. Other than that, it also assesses the lighting, ventilation, and drainage system of the premises.

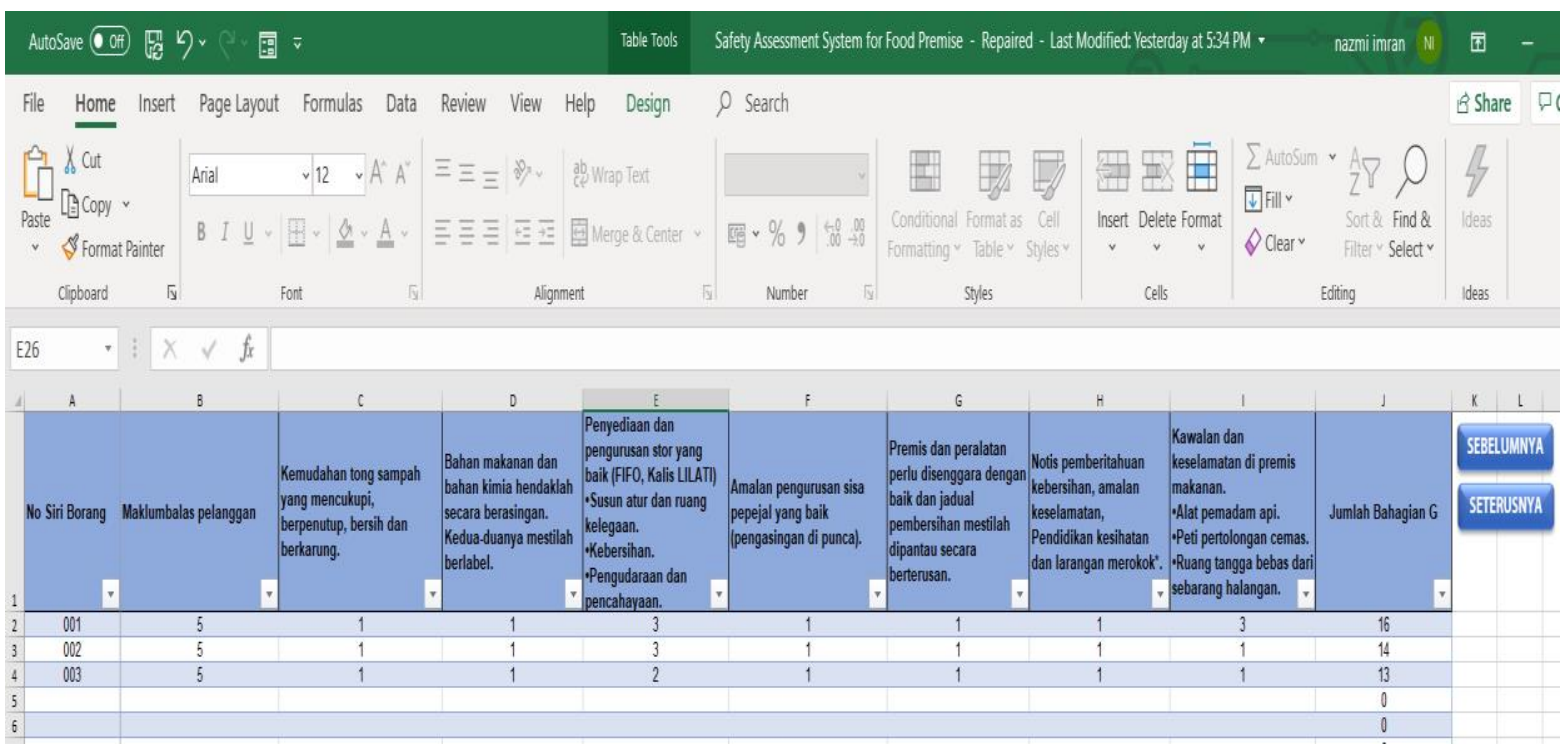

Figure 13: Section G

The interface in Figure 13 allows users to fill up the score on the other part of the assessment. It has eight elements covering the parts other than previous sections. Some of the elements are the customers' feedbacks, store management, and safety equipment available at the premise such as fire extinguishers and first aid kits.

\section{Data Validation}

The maximum marks for each element assessed were referred to the Local Government Department by referring to the Guideline for Grading Systems for Food Premises in Local Authority Areas from the Ministry of City Welfare, Housing and Local Government (2014). Data validation in this system would guide the user to enter the score based on the information and prevent human errors while doing the assessment. A guide notification will appear whenever the user clicks on the scoring column. A warning error notification will appear if the score entered is not within the acceptable range. Figure 14 shows the example of guide notification while Figure 15 shows the notification of error. 


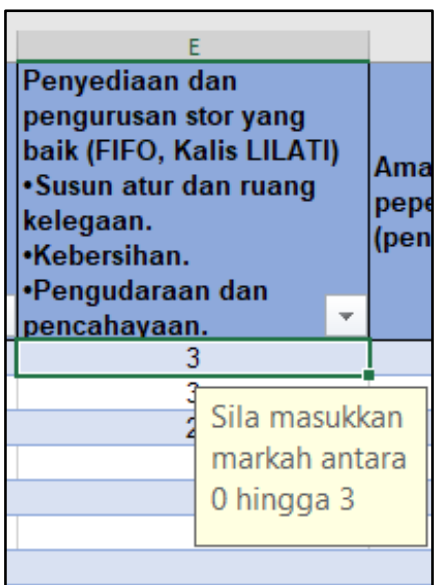

Figure 14: Guide Notification.

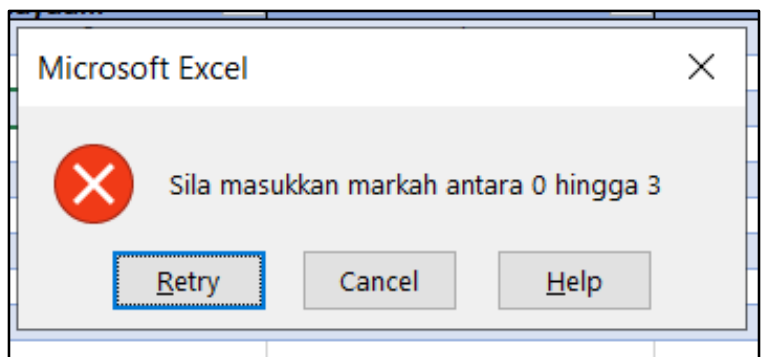

Figure 15: Notification of Error

\section{Premise Grading Page Interface}

This page is used to calculate the total score after the safety assessment is done, and the grade will be obtained by the food premise. This page is also linked with other pages using the form serial number. The total score from each section is automatically transferred to this page. The final score is calculated by summing up the score from each section. After that, the grade obtained by the premise is generated based on the final score. Figure 16 shows the premise grading page interfere.

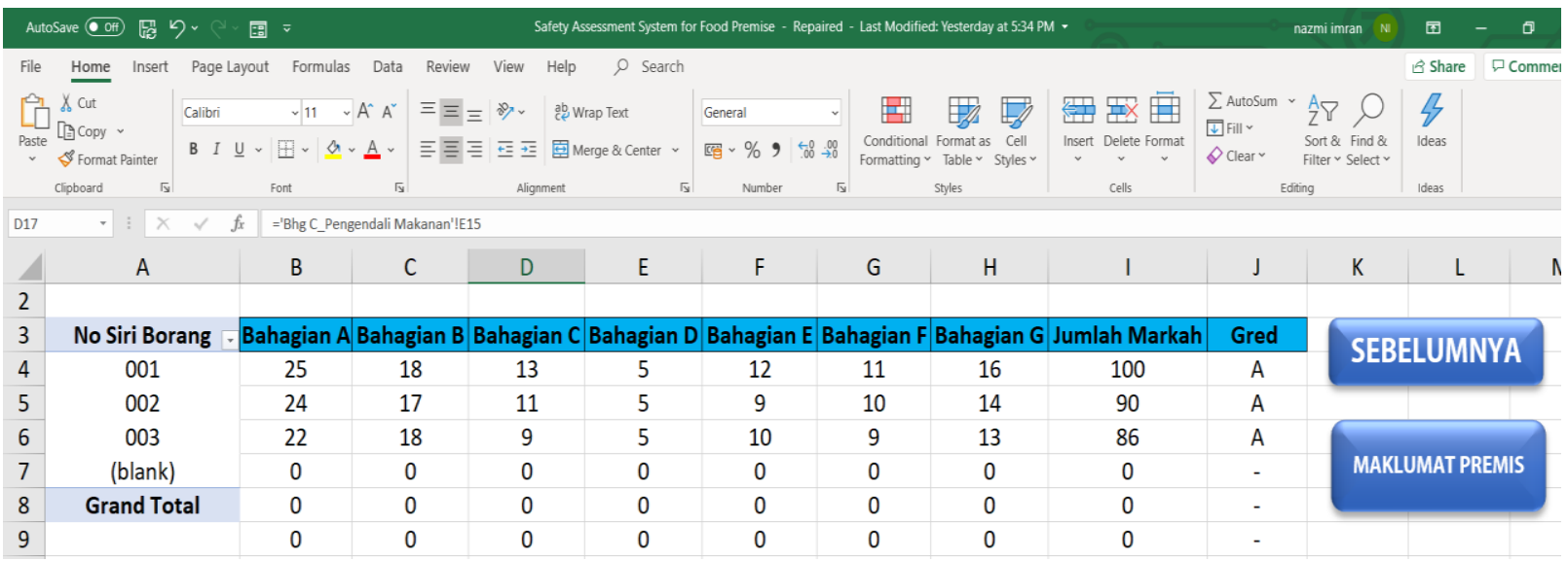

Figure 16: Premise Grading Page

\section{VALIDATION OF THE PROTOTYPE SYSTEM System Usability Scale (SUS) Test}

The standard SUS questionnaire was distributed among the potential end-users of this system which are the local authorities and owners of food premises. About 12 potential end-users were in answering the questionnaire. Figure 17 shows the scoring result of the SUS test questionnaire. 


\begin{tabular}{|c|c|c|c|c|c|c|c|c|c|c|}
\hline User & Question 1 & Question 2 & Question 3 & Question 4 & Question 5 & Question 6 & Question 7 & Question 8 & Question 9 & Question 10 \\
\hline User 1 & 4 & 5 & 4 & 3 & 4 & 2 & 4 & 2 & 4 & 2 \\
\hline User 2 & 4 & 4 & 4 & 3 & 4 & 3 & 4 & 2 & 3 & 2 \\
\hline User 3 & 4 & 3 & 2 & 4 & 3 & 4 & 1 & 4 & 3 & 3 \\
\hline User 4 & 5 & 1 & 5 & 1 & 5 & 1 & 5 & 1 & 5 & 1 \\
\hline User 5 & 4 & 5 & 5 & 2 & 4 & 2 & 5 & 4 & 4 & 2 \\
\hline User 6 & 4 & 5 & 5 & 1 & 5 & 2 & 5 & 4 & 4 & 2 \\
\hline User 7 & 4 & 3 & 3 & 3 & 4 & 3 & 3 & 3 & 4 & 3 \\
\hline User 8 & 4 & 4 & 4 & 3 & 4 & 3 & 4 & 2 & 3 & 2 \\
\hline User 9 & 5 & 1 & 5 & 1 & 5 & 1 & 5 & 1 & 5 & 1 \\
\hline User 10 & 4 & 3 & 5 & 3 & 4 & 2 & 4 & 2 & 4 & 3 \\
\hline User 11 & 4 & 3 & 5 & 3 & 4 & 2 & 4 & 2 & 4 & 3 \\
\hline User 12 & 4 & 1 & 4 & 2 & 4 & 2 & 4 & 2 & 3 & 4 \\
\hline
\end{tabular}

Figure 17: Scoring Result from SUS Test Questionnaire

Based on the score result shown in Figure 17, the overall score is calculated to get the average score, and then the grade is referred to the grading curve scale as mentioned by Lewis and Sauro (2018). Figure 18 shows the final SUS score for this system.

Odd Number Question $=$ Score -1

Even Number Question $=5-$ Score

SUS Final Score $=$ SUS Raw Score $x 2.5$

Average $=$ Sum of SUS Final Score $/ 12$

\begin{tabular}{|c|c|c|c|}
$\begin{array}{c}\text { Sum of Odd- } \\
\text { Numbered } \\
\text { Question Score }\end{array}$ & $\begin{array}{c}\text { Sum of Even- } \\
\text { Numbered } \\
\text { Question Score }\end{array}$ & $\begin{array}{c}\text { SUS Raw } \\
\text { Score }\end{array}$ & $\begin{array}{c}\text { SUS Final } \\
\text { Score }\end{array}$ \\
\hline 20 & 14 & $\mathbf{2 6}$ & $\mathbf{6 5}$ \\
\hline 19 & 14 & $\mathbf{2 5}$ & $\mathbf{6 2 . 5}$ \\
\hline 13 & 18 & $\mathbf{1 5}$ & $\mathbf{3 7 . 5}$ \\
\hline 25 & 5 & $\mathbf{4 0}$ & $\mathbf{1 0 0}$ \\
\hline 22 & 15 & $\mathbf{2 7}$ & $\mathbf{6 7 . 5}$ \\
\hline 23 & 14 & $\mathbf{2 9}$ & $\mathbf{7 2 . 5}$ \\
\hline 18 & 15 & $\mathbf{2 3}$ & $\mathbf{5 7 . 5}$ \\
\hline 19 & 14 & $\mathbf{2 5}$ & $\mathbf{6 2 . 5}$ \\
\hline 25 & 5 & $\mathbf{4 0}$ & $\mathbf{1 0 0}$ \\
\hline 21 & 13 & $\mathbf{2 8}$ & $\mathbf{7 0}$ \\
\hline 21 & 13 & $\mathbf{2 8}$ & $\mathbf{7 0}$ \\
\hline 19 & 11 & $\mathbf{2 8}$ & $\mathbf{7 0}$ \\
\hline & Average & $\mathbf{2 7 . 8}$ & $\mathbf{6 9 . 6}$ \\
\hline & & &
\end{tabular}

Figure 18: Final SUS Score

Result obtained from the System Usability Scale (SUS) test is 69.6. Based on the result of the System Usability Scale (SUS) test, the grade achieved for the system is $\mathrm{C}$ which is considered as an average grade for a system. A study by Peres et al. (2013) stated that the SUS score above 68 is considered as average, while a score below 68 is considered as below average. The scoring system that achieved 68 or Grade $\mathrm{C}$ is considered useable and needs additional improvements (SUS, 2019).

\section{CONCLUSION}

In conclusion, this study succeeds in developing the safety assessment system for food premises based on the criteria stated in the Food Act 1983 and the Guideline for Grading System for Food Premises in Local Authority Areas. Besides, this study also succeeds to validate the system in terms of its usability from two groups of end-users which are the local authorities and the food premise owners. This current prototype of a safety assessment system is very important to assess the compliance of regulations that can be used by the local authority and the occupier of the food premises. Moreover, it will also guide the occupier to maintain the safety of their food and premises.

\section{ACKNOWLEDGEMENT}

The authors would like to acknowledge Faculty of Industrial Sciences and Technology, Universiti Malaysia Pahang for the financial support and resources (RDU190388), the research information from the practitioners and respondents to make this study feasible. 


\section{REFERENCES}

Abdul-Mutalib, N.A., Syafinaz, A.N., Sakai, K. and Shirai, Y. (2015). An overview of foodborne illness and food safety in Malaysia. 22(3), 896-901.

Abdul-Mutalib, N. A., Abdul-Rashid, M. F., Mustafa, S., Amin-Nordin, S., Hamat, R. A., \& Osman, M. (2012). Knowledge, attitude and practices regarding food hygiene and sanitation of food handlers in Kuala Pilah, Malaysia. Food Control, 27(2), $289-293$. https://doi.org/10.1016/j.foodcont.2012.04.001

Angelillo, I. F., Viggiani, N. M. A., Rizzo, L., \& Bianco, A. (2000). Food Handlers and Foodborne Diseases : Knowledge, Attitudes , and Reported Behavior in Italy. 63(3), 381-385.

Aziz, H. A., Shariff, A. M., Rusli, R., \& Yew, K. H. (2014). Managing process chemicals , technology and equipment information for pilot plant based on Process Safety Management standard. Process Safety and Environmental Protection, 92(5), $423-429$. https://doi.org/10.1016/j.psep.2014.02.011

Bou-Mitri, C., Mahmoud, D., El Gerges, N., \& Jaoude, M. A. (2018). Food safety knowledge, attitudes and practices of food handlers in lebanese hospitals: A cross-sectional study. Food Control, 94(April), 78-84. https://doi.org/10.1016/j.foodcont.2018.06.032

Department of Statistics Malaysia. (2015). Compendium of Environment Statistics 2016. Department of Statistics Malaysia, June, 59.

Dora-liyana, A. L., Mahyudin, N. A., \& Ismail-fitry, M. R. (2018). Food Safety and Hygiene Knowledge , Attitude and Practices among Food Handlers at Boarding Schools in the Northern Region of Malaysia Food Safety and Hygiene Knowledge, Attitude and Practices among Food Handlers at Boarding Schools in the Northern Region. 8(17), 238-266. https://doi.org/10.6007/IJARBSS/v8-i17/5228

Hertzman, J., \& Barrash, D. (2007). An assessment of food safety knowledge and practices of catering employees. British Food Journal, 109(7), 562-576. https://doi.org/10.1108/00070700710761545

Ismail, F. H., Chik, C. T., Muhammad, R., \& Mat, N. (2016). Food Safety Knowledge and Personal Hygiene Practices amongst Mobile Food Handlers in Shah Alam , Selangor. Procedia - Social and Behavioral Sciences, 222, $290-298$. https://doi.org/10.1016/j.sbspro.2016.05.162

Lee, H. K., Halim, H. A., Thong, K. L., \& Chai, L. C. (2017). Assessment of Food Safety Knowledge , Attitude , Self-Reported Practices , and Microbiological Hand Hygiene of Food Handlers. International Journal of Environmental Research and Public Health, 55, 14. https://doi.org/10.3390/ijerph14010055

Lewis, J. R., \& Sauro, J. (2018). Item Benchmarks for the System Usability Scale. Journal of Usability Studies, 13(3), $158-167$.

Ministry of Health. (2014). Annual report 2014. Annual Report, Food Safety and Quality Division, 52.

Ministry of Housing and Local Government. (2014). Garis Panduan Sistem Pengredan Premis Makanan di Kawasan Pihak Berkuasa Tempatan, 5(4), 1-40.

Mun, S. G. (2020). The effects of ambient temperature changes on foodborne illness outbreaks associated with the restaurant industry. International Journal of Hospitality Management, 85(November 2019), 102432. https://doi.org/10.1016/j.ijhm.2019.102432

Peres, S. C., Pham, T., \& Phillips, R. (2013). Validation of the system usability scale (sus): Sus in the wild. Proceedings of the Human Factors and Ergonomics Society, September 2013, 192-196. https://doi.org/10.1177/1541931213571043

Saad, M., Poh, T., Azam, M., \& Adil, M. (2013). Hygiene Practices of Food Handlers at Malaysian Government Institutions Training Centers. Procedia - Social and Behavioral Sciences, 85, 118-127. https://doi.org/10.1016/j.sbspro.2013.08.344

Sani, N. A., Saba, C. K. S., Asghar, A., Obadina, A. O., Odeyemi, O. A., Abughoush, M., Bamidele, F. A., Dongmo, F. F. D., Aberoumand, A., \& Macer, D. (2018). Food safety knowledge, attitudes and practices among consumers in developing countries: An international survey. Food Research International, 116 (October 2018), $1386-1390$. https://doi.org/10.1016/j.foodres.2018.10.030

Sani, N. A., \& Siow, O. N. (2014). Knowledge, attitudes and practices of food handlers on food safety in food service operations at the Universiti Kebangsaan Malaysia. Food Control, 37, 210-217. https://doi.org/10.1016/j.foodcont.2013.09.036

Shafie, A. A., \& Azman, A. W. (2015). Assessment of knowledge, attitude and practice of food allergies among food handlers in the state of Penang, Malaysia. Public Health, 1-7. https://doi.org/10.1016/j.puhe.2015.03.016

World Health Organization. (2015). World Health Day 2015 CampaiGn tool kit. 11. 


\section{AUTHORS' BIOGRAPHY}

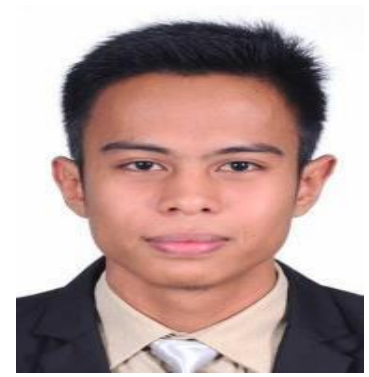

Nazmi 'Imran Makhilan is a student at Universiti Malaysia Pahang. He is currently pursuing his study at the Faculty of Industrial Science and Technology.

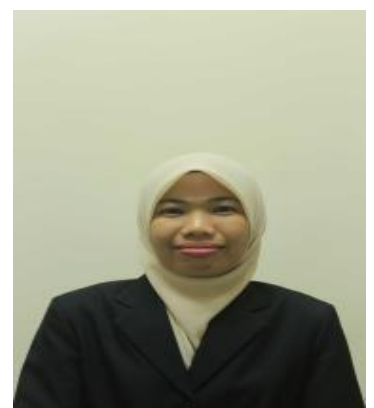

Nur Syafiqah Fauzan is a lecturer at the Faculty of Industrial Science and Technology, Universiti Malaysia Pahang. Her research activities mainly focusing on occupational health, occupational safety and environmental health. 